\title{
O EVENTO LIMITE EM PRIMO LEVI: UMA LEITURA DE OS AFOGADOS E OS SOBREVIVENTES
}

http://dx.doi.org/10.11606/issn.2237-1184.v0i32p51-72

Pedro Spinola Pereira Caldas ${ }^{\mathrm{I}}$

\section{RESUMO}

No presente artigo, pretendo pensar o conceito de evento a partir de uma leitura de Os afogados e os sobreviventes, de Primo Levi. Considerando que o evento limite é, segundo Saul Friedländer, o evento capaz de testar as categorias tradicionais de conhecimento e representação, assumo que seria possível uma inversão, na qual o texto do sobrevivente - como é o caso de Levi - pode servir não de prova documental ou descrição da experiência limítrofe, mas de estrutura conceitual. Aqui, entendo o limite a partir de uma relação com o outro: o limite de falar como um outro de si mesmo, o limite de falar para o outro, o limite de falar pelo outro e o limite de falar do outro.

\section{ABSTRACT}

In this article, I reflect on the concept of limit event based on an appreciation of Primo Levi's work The Drowned and the Saved. Considering that a limit event, in accordance with Saul Friedländer's view, is an event with the capacity to test the traditional categories of knowledge and representation, I assume it is possible to undertake an inversion, in which a survivor's text - as in Levi's case - may serve not as documental evidence or as a description of a limit experience, but, instead, as a conceptual structure, I understand the notion of limit, here, based on a relationship with the other: as the limit to speak as another about oneself, as the limit to speak to the other, as the limit to speak for the other, and as the limit to speak of the other.

\author{
PALAVRAS-CHAVE: \\ Primo Levi; \\ Os afogados e os sobreviventes; \\ evento limite; \\ Holocausto.
}

\section{KEYWORDS}

Primo Levi;

The Drowned and the Saved; limit event;

Holocaust.

\footnotetext{
I Universidade Federal do Estado do Rio de Janeiro, Rio de Janeiro, Rio de Janeiro, Brasil.
} 


\section{" $\mathrm{E}$}

u sou um centauro. E o sou porque duplo, híbrido, bifurcado. Sou italiano e judeu, químico e escritor, racionalista e poeta. Sou absolutamente sedentário e me agrada viajar" (CI, III, p. 454). ${ }^{1}$ É assim como Primo Levi se definiu em uma entrevista, concedida em junho de 1984. E eu ousaria acrescentar: leitor de ciências naturais e de historiografia. ${ }^{2}$ A minha ousadia, porém, tem algum fundamento. Em uma entrevista dada a Ferdinand Camon - também na década de 80 - Levi faz o seguinte comentário sobre o suposto aspecto moderno dos campos de extermínio:

[...] esta comparação do mundo com o Lager, em nós - nós "tatuados", nós "marcados" - suscita uma revolta: não, não é assim, não é verdade que a Fiat seja um Lager, que um hospital psiquiátrico seja um Lager: não há câmera de gás na Fiat; se está muito mal no hospital psiquiátrico, ${ }^{3}$ mas não há o forno, há um caminho de saída, se recebem os parentes [...] Todavia, e este é o segundo tempo, podem valer como metáfora. Eu mesmo o escrevi em É isto um homem? que o Lager era um espelho da situação externa, mas um espelho deformante [...] (IP, III, p. 837)

Está implícito o conhecimento de Levi sobre a Historikerstreit ("a querela dos historiadores"), o que pode ser comprovado em um breve ensaio seu, chamado "O buraco negro de Auschwitz" (PS, II, p. 163-5). Todavia, é possível ver nesse trecho mais do que a reprodução de uma informação bem assimilada. Nele há outro ponto interessante: a imagem do "espelho deformante", ${ }^{4}$ metáfora que antecipa uma formulação muito precisa do grande historiador Saul Friedländer para um tema que me interessa em especial, a saber, o da definição do evento limite: ${ }^{5}$

\footnotetext{
1 As obras de Primo Levi, reunidas por Marco Belpoliti em Opere Complete (2016; 2018), serão referenciadas aqui pela sigla de suas iniciais, seguidas do volume na qual se encontram. São elas: L'altrui mestiere [AM, II], I sommersi e i salvati [SES, II], Interviste postume [IP, II], Pagine Sparse [PS, II], Racconti e saggi [RS, II] e Conversazioni e interviste [CI, III].

2 Para uma análise da biblioteca sobre o Holocausto de Primo Levi, nela incluída a Historiografia sobre o assunto, cf. GORDON, 2012, p. 1145-791.

${ }^{3}$ Não obstante as reservas de Levi, seu pensamento foi fundamental para a luta antimanicomial na Itália, como se pode aprender com o texto de Massimo Bucciantini. Já em 1967, o livro Che cos'è la psichiatria, de Franco Basaglia, faz uma apropriação de É isto um homem? para além do universo da representação Resistência e dos campos de concentração. Cf. BUCCIANTINI, 2019.

${ }^{4} \mathrm{O}$ tema do espelho na obra de Levi foi até tema de um de seus contos, "O fabricante de espelhos" / "Il fabriccante di Specchi", cf. RS, II, p. 1055-8.

${ }_{5}$ Para uma boa análise da origem do conceito de evento limite na filosofia de Karl Jaspers, cf. BORNEMARK, 2006.
} 
O extermínio dos judeus na Europa está acessível tanto à representação quanto à interpretação como qualquer outro evento histórico. Mas estamos lidando com um evento que testa nossas categorias tradicionais de ordem conceitual e representacional, um "evento limítrofe" ("event at the limits")

O que faz da "Solução Final" um evento limítrofe é o próprio fato de ser a forma mais radical de genocídio encontrada na história: a tentativa absoluta, deliberada, sistemática, industrialmente organizada e largamente bem-sucedida de exterminar todo um grupo humano no seio da sociedade ocidental no século $X X$ (FRIEDLÄNDER, 1992, p. 2-3).

Friedländer caracteriza bem o evento limite: uma ferramenta moderna, ou seja, a ciência histórica é insuficiente, embora não de todo impotente, para compreender uma ação também moderna, isto é, uma ação cuja característica é ter sido "industrialmente organizada". Como disse Jean-François Lyotard, Auschwitz foi um terremoto que destruiu vidas, ambiente, edificações, mas também o sismógrafo capaz de medi-lo e quantificá-lo (apud FRIEDLÄNDER, 1999, p. 22). Ao testar categorias, o evento limítrofe perde sua função de objeto e passa a ditar as regras do jogo, dizendo em que momento determinados procedimentos deixam de funcionar.

Todavia, não se trata somente de uma questão solúvel através da substituição de um modelo obsoleto por outro mais eficaz, pois a essência do problema está expressa na imagem do espelho deformante: a imagem deformada é a imagem de si, assim como são nossas (dos historiadores, digamos) as categorias tradicionais. ${ }^{6}$ Estamos implicados nelas. O evento limite nos afeta, e nos afeta possivelmente porque nos devolve uma imagem deformada, e não por causa da sua ausência. ${ }^{7}$

Partindo desse ponto, ou seja, assumindo, de um lado, a insuficiência das ditas categorias, mas sem ceder ao argumento da inefabilidade, decidi, então, propor o seguinte exercício: reconhecendo a riqueza da imagem de Levi, poderíamos tentar compreender o significado de evento limite tomando como base o texto do sobrevivente. ${ }^{8}$ Afinal, se o sismógrafo está realmente quebrado, deveríamos deixar as nossas ditas

\footnotetext{
${ }^{6}$ Para uma tentativa de identificação das categorias testadas, cf. CALDAS, Pedro S. P. "O conceito de evento limite": Uma análise de seus diagnósticos. Tempo, v. 25, n. 3, set-dez. 2019.

7 Esse me parece ser o problema da definição de evento limite em Dominick LaCapra, que o compreende da seguinte forma: "[...] pode-se [...] definir evento limite como o evento que ultrapassa a capacidade da imaginação em concebê-lo ou antecipá-lo [...] incluindo a imaginação daqueles que não o experimentaram" (LaCAPRA, 2004, p. 132-3). A ultrapassagem da imaginação pode significar a sua ausência, a sua dificuldade em produzir uma imagem.

8 Como muito bem disse Matteo Cavalleri, a obra de Levi nos permite pensar em "[...] uma epistemologia que não pode se manifestar em um processo conceitual, mas que se encarrega, e disto se aproveita, da reativação de uma disposição representativa, de um Standpunkt representativo que se reanima graças à redescoberta de sua natureza intersubjetiva" (CAVALLERI, 2017, p. 43).
} 
categorias de lado, pelo menos por um pouco ou em caráter experimental, e passarmos a ler a escrita de um sobrevivente menos como documento descritivo de situações extremas e mais como cerne de uma teoria. Não estou propondo nada de novo: Neil Levi e Michael Rothberg já mostraram como "[Primo] Levi abre caminho para a conceptualização do universo concentracionário como terra de fronteira (Borderland)" (LEVI, N.; ROTHBERG, 2003, p. 33). Meu exercício, portanto, tem um objetivo bem específico, qual seja, o de qualificar melhor esse limite, ver as relações nas quais ele se inscreve, evitando o binarismo possível na relação entre sujeito impotente e objeto resistente. Prefiro, portanto, apostar naquilo que Domenico Scarpa viu na obra de Levi, ou seja, uma grande conquista de "aumento do dizível" (SCARPA, 2015, p. 137). O limite, então, não pode ser somente um sinal de impedimento, mas um lugar onde se pode explorar uma riqueza vocabular.

Essa ideia surgiu a partir de uma releitura de Os afogados e os sobreviventes, durante a qual pude notar, com um quê do "olhar infantil" interessado em catar pequenos restos pelo chão (cf. BENJAMIN, 2013, p. 16), algumas pistas, alguns "desperdícios" que passaram desapercebidos quando ainda tentava desvendar a estrutura do texto e compreender melhor seus principais conceitos, como "zona cinza" 9 ou "vergonha". Uma vez reunidos, esses "restos" apontam para uma interessante variação semântica alusiva a várias formas de experiência do limite. ${ }^{10}$

Já no primeiro capítulo ("A memória da ofensa"), por exemplo, é possível encontrar algumas passagens expressivas, quase todas sobre o ato de rememorar: "pretendo examinar aqui as recordações de experiências extremas, de ofensas sofridas ou impingidas" (SES, II, p. 1155); ou ainda, "[...] a distinção entre verdadeiro e falso perde progressivamente os seus contornos [...]" (SES, II, p. 1157) e "como caso limite da deformação da recordação há a sua supressão" (SES, II, p. 1160), e, assim, "[...] o melhor modo para se defender da invasão das memórias é impedir-lhe a entrada, estender uma barreira sanitária ao longo de seus confins" (Idem). "Extremo", "contornos", "confins", e, claro, "caso limite", a meu ver, fazem referência à experiência do limite.

Não coincidentemente, logo no início do capítulo seguinte, o termo "confins" reaparece quando Levi relembra a sensação vivida na chegada ao Lager: "o mundo no qual se era jogado era sim terrível, mas também indecifrável: não era conforme a algum modelo, o inimigo estava ao redor, mas também dentro, o 'nós' perdia seus confins [...]" (SES, II, p. 1165). Na mesma página, poucas linhas acima, uma derivação mais sutil: "em quem

\footnotetext{
9 Uso aqui o termo "zona cinza", tradução literal do italiano, ao invés de "zona cinzenta". Devo isso a uma conversa informal com Anna Basevi, que me fez essa observação que só então me pareceu evidente.

${ }^{10}$ Somente após concluir este artigo tive contato e acesso a um artigo de Gianluca Cinelli, e que trata exatamente sobre a ideia de limite na recepção na obra de Levi do romance Moby Dick, de H. Melville. Cf. CINELLI, 2020.
} 
lê (ou escreve) hoje a história do Lager tem a tendência, ou antes a necessidade, de dividir o mal do bem [...] sobretudo, os jovens pedem clareza, o corte claro" (Idem). Ainda no mesmo capítulo, cujo título "Zona cinza" aponta para "contornos mal definidos" (SES, II, p. 1168): "um casolimite de colaboração é representado pelos Sonderkommandos de Auschwitz e de outros Lager de extermínio" (SES, II, p. 1173).

Por fim, no capítulo sobre a violência inútil encontrei o seguinte trecho: "gostaria ainda de acenar, como exemplo extremo de violência ao mesmo tempo estúpida e simbólica, ao uso ímpio que foi feito (não aleatoriamente, mas com método) do corpo humano como se fosse um objeto" (SES, II, p. 1223). De novo voltam termos como "confins", "extremo", "caso limite", "contorno", e ainda um novo: "corte". Como se pode ver, não faltam termos que, com alguma boa vontade semântica, se agrupam em volta da experiência do limite. Mas a pergunta é: o que fazer com esta colheita?

Os "restos" do texto poderiam, então, ser recompostos em uma rede capaz de articular dimensões distintas da elaboração do evento limite. Em um primeiro momento, nota-se uma tensão na relação do sobrevivente consigo mesmo ("como caso limite da deformação da recordação há a sua supressão"), e, assim, abre-se uma fissura entre o presente e o passado do próprio sobrevivente.

Mesmo que o sobrevivente consiga testemunhar, sua tarefa não terminaria aí, pois não é possível também deixar de notar outra fissura, agora na comunicação entre o sobrevivente e seu público ouvinte, ansioso por um "corte" nítido, mas cujo desejo de compreensão não necessariamente poderá ser atendido. Um limite não da representação, como o anterior, mas o da escuta, como nos relatos do Lager que não encontravam ouvintes, seja por desinteresse, seja pela expectativa de narrativas padronizadas. ${ }^{11}$ De toda forma, a narrativa do testemunho não tem acolhida garantida. ${ }^{12}$

É possível também perceber um terceiro limite se desenhando, mais precisamente o inscrito entre o presente do sobrevivente e o passado de outros prisioneiros, como o dos "afogados" e dos membros dos Sonderkommandos ("um caso-limite de colaboração é representado pelos Sonderkommandos de Auschwitz e de outros Lager de extermínio"), e, por fim, um limite se configura na incompreensão da intenção dos algozes, daqueles que exerceram a "violência inútil" ("exemplo extremo de violência ao mesmo tempo estúpida e simbólica").

\footnotetext{
11 O desinteresse, por exemplo, era percebido pelo próprio Levi e característico dos primeiros anos do pós-Guerra, como fica claro em seu breve texto "Anniversario", de 1955 (cf. PS, II, p. 1291-4). Já o oposto, o sucesso que, para ser, precisa ser diluído em procedimentos narrativos consagrados também é detectado por Levi em seu texto sobre a minissérie Holocausto, de 1979 (cf. PS, II, p. 1453-60).

12 O conceito de testemunho não será elaborado sistematicamente aqui, pois causaria uma sobreposição de conceitos, e algumas referências irão aparecer de forma diluída no texto.
} 
Portanto, haveria pelo menos quatro linhas demarcatórias de um limite, e todas elas apontam para formas distintas de alteridade. O limite se inscreve quando o sobrevivente fala de si como um outro (que sobreviveu), mas também ao falar para o outro (que escuta), ao falar pelo outro (que sucumbiu) e ao falar de um outro (que ofendeu). Ainda que sem pretender restaurar ou construir uma totalidade de sentido, ${ }^{13}$ não gostaria também de renunciar à intenção de relacioná-los. Se conseguir, talvez seja possível desenhar aqui um "sistema de cicatrizes" (ADORNO, 2015, p. 48). Na sequência, irei expor estas quatro experiências de limite (como / para / pelo / de) dispersas em Os afogados e os sobreviventes.

\section{O limite de falar como um outro}

Recuperando a expressão retirada do capítulo "A memória da ofensa" e apresentada na introdução: "pretendo examinar aqui as recordações de experiências extremas, de ofensas sofridas ou impingidas" (SES, II, p. 1155), cuja importância jamais poderia ser subestimada, pois "é natural e óbvio que o material mais consistente para a reconstrução da verdade sobre os campos seja constituído pelas memórias dos sobreviventes" (SES, II. p. 1150).

Todavia, Levi reconhece prontamente o quão complexa é essa posição do testemunho de si, uma vez que "neste caso estão operando todos ou quase todos os fatores que podem obliterar ou deformar o registro mnemônico: a recordação de um trauma, sofrido ou imposto, é ela mesma traumática" (Idem, p. 1155-6) Estamos aqui no âmbito do limite em falar de si como um outro de si que sobreviveu, e o uso da palavra trauma ${ }^{14}$ é bastante expressivo. E, assim, o presente é dominado por um passado do qual o sobrevivente tem grande dificuldade em se libertar. Para além dessa condição patológica, as testemunhas, além de estarem falecendo gradualmente, "[...] dispõem de recordações cada vez mais desfocadas e estilizadas; frequentemente, e de modo involuntário, influenciadas por notícias recebidas por eles somente mais tarde, ou de leituras ou narrativas

${ }^{13}$ Tentar dar um sentido totalizante ao livro iria contra sua própria história de criação. Como disse Martina Mengoni: "Levi deu uma forma híbrida a Os afogados e os sobreviventes. Histórias, estórias e questionamentos se sobrepõem e se interseccionam umas com as outras, tornando possível partilhar com os leitores partilhar os vários estágios de uma viagem e de uma reflexão" (MENGONI, 2015, p. 155).

14 As palavras de Levi condizem com a descrição feita pelo psiquiatra Bessel van der Kolk, professor de na Universidade de Boston: “Enquanto o trauma não é resolvido, os hormônios do stress que o corpo armazena para sua própria proteção continuam circulando, e os movimentos defensivos e as respostas emocionais continuam a ser reencenadas [...] Pessoas que sofrem de flashbacks geralmente organizam suas vidas tentando se proteger deles"(VAN DER KOLK, 2014, p. 66-7). Por sua vez, a mesma se reproduz na formulação teórica de um historiador como Frank Ankersmit, para quem "[...] a experiência traumática é terrível demais para ser admitida conscientemente. [...] Característico do trauma é a incapacidade de realmente sofrer com a própria experiência traumática" (ANKERSMIT, 2005, p. 335). Para uma história do conceito de trauma, cf. LUCKHURST, 2008. Para uma ótima visão de conjunto, cf. CARUTH 2014. 
alheias" (Idem). Isso não necessariamente significa passividade ou ingenuidade, mas algo presente na natureza da experiência no Lager, ou seja, o veto a uma perspectiva (cf. SES, II, p. 1150-1), a um olhar que não fosse aquele para o chão e guiado por uma cabeça curvada, expressão do o prisioneiro que "se sentia, em suma, dominado por um enorme edifício de violência e de ameaça, mas não podia construir para si, a partir dali, uma representação, porque os seus olhos estavam amarrados ao chão por uma carência de todos os minutos" (SES, II, p. 1151).

O limite entre o presente e o passado do próprio sobrevivente, portanto, é o limite marcado pela dificuldade em recordar a impossibilidade de se "construir uma representação", mesmo porque a estilização não é necessariamente uma cobertura ideológica, uma falsa máscara a organizar a experiência alheia, mas, segundo Levi, algo fundado em uma base mais profunda, pois a realidade dos campos era essencialmente não narrativa, como ele mesmo disse em maio de $1984 \mathrm{em}$ uma entrevista a Marco Vigevani. Perguntado "como pôde [...] reviver psicologicamente e exprimir em palavras uma experiência que está no limite do humano e do inimaginável", Levi responde: "eu me dou conta que é muito difícil transformar em palavras essa experiência", para especificar que "a coisa mais difícil de dar conta era o 'tédio', o tédio total, a monotonia, a ausência de eventos, os dias todos iguais. [...] O passado fica comprimido [...] não tinha espessura" (CI, III, p. 439).15 Portanto, a estilização não é obrigatoriamente uma falsificação, e mais: toda narrativa parece ser desde sempre uma estilização, na medida em que "[...] na memória acontece exatamente o contrário: prevalecem e invadem-na os episódios singulares, clamorosos, terríveis, ou, ao contrário, os positivos, mas, enquanto são vividos, são inseridos em um tecido totalmente desintegrado" (Idem). Nesse sentido, a própria expressão evento limite poderia perder o sentido, pois sequer evento haveria, ou, para ser mais preciso, ele seria indeterminado e só poderia ser visualizado dentro da moldura de uma narrativa.

Um caminho possível para superar esse aparentemente intransponível obstáculo estaria no processo de decantação, " [...] graças ao qual os fatos históricos, somente algumas décadas após a sua conclusão, adquirem o seu chiaroscuro e a sua perspectiva" (SES, II, p. 1152). Afinal, uma vez que, conforme ocorre amiúde com a pesquisa histórica, "os dados quantitativos sobre a deportação e sobre os massacres nazistas, no Lager e em outros lugares, ainda não haviam sido obtidos" (Idem).

Todavia, não podemos depositar todos os nossos esforços na decantação: o distanciamento temporal, em grande parte capaz de servir de útero para

${ }^{15}$ Para uma discussão sobre como Levi, de alguma maneira, se aproxima das teses de George Steiner sem, todavia, jamais pender totalmente para o argumento da inefabilidade, cf. GORDON, 2001, p. 76-8. 
o lento desenvolvimento de uma perspectiva, não coincide com a própria temporalidade na qual Levi insere a escrita de Os afogados e os sobreviventes.

Este livro [...] se propõe [...] um fim mais ambicioso: gostaria de responder à pergunta mais urgente, à pergunta que angustia todos que tiveram a oportunidade de ler nossas narrativas: o quanto do mundo concentracionário morreu e não retornará mais, como a escravidão e o código dos duelos? O quanto já retornou ou está retornando? (SES, II, p. 1153)

O trecho acima deve ser lido com atenção, e não somente porque nele está anunciado o propósito da obra, mas porque nos remete à importância da dimensão temporal do Lager apontada por Primo Levi. Portanto, como seria possível um processo de decantação, se a temporalidade insinuada nas palavras acima pressupõe a impossibilidade do distanciamento necessário à construção de uma perspectiva? Afinal, a inquietação inicial de Levi consiste no questionamento da existência do passado efetivamente distante e estranho, como o código dos duelos, realmente presente como latência, como aparece no livro várias vezes em referências a regimes autoritários ainda existentes no século XX após a Segunda Guerra, e potencialmente vivo como ameaça. ${ }^{16}$

Por isso, por se destinar também ao presente - e ao futuro - e mais do que meramente informar seus leitores sobre o passado, Os afogados e os sobreviventes não é somente um livro sobre a memória de um evento traumático, mas uma reflexão sobre a capacidade de nos reconhecermos nele. Portanto, precisará enfrentar também outro limite, certamente não o da representação da parte do sobrevivente, mas o de quem não passou pela experiência: o limite da escuta, intensamente expresso em Os afogados e os sobreviventes: "para nós, falar com os jovens é sempre mais difícil. Percebemo-lo como um dever, e, ao mesmo tempo, como um risco: o risco de parecermos anacrônicos, e de não sermos escutados" (SES, II, p. 1273). O livro é também para esse outro, seu contemporâneo. ${ }^{17}$

\footnotetext{
16 Não deixa de ser interessante, portanto, notar aqui a articulação de uma concepção temporal símile à "teoria dos dois momentos" na qual Jean Laplanche, em entrevista concedida a Cathy Caruth (2014, p. 396), apresenta sua interpretação da estrutura da experiência traumática em Freud, na qual o evento traumático consiste no reinvestimento posterior de um evento implantado de fora em um primeiro momento $\mathrm{O}$ mesmo vale para o conceito de "cotemporalidade", tal como proposto por Lawrence Langer ao falar dos testemunhos de sobreviventes do Holocausto registrados nos arquivos Fortunoff, da Universidade de Yale. cf. LANGER, 1991, p. 3.

${ }_{17}$ Como deixaram bem claro Anna Bravo e Danielle Jalla (1991, p. 73-4), "o livro é um balanço da relação entre o Lager e a consciência contemporânea", entenda-se: a consciência do final da década de 70 e início da década de 80, que incluía, entre outras situações, a do revisionismo e, pior, do negacionismo de um Robert Faurisson.
} 


\title{
O limite em falar para o outro
}

"Fomos capazes, nós, os sobreviventes, de compreender e fazer compreender a nossa experiência?" (SES, II, p. 1164).18 Com essa dúvida começa o consagrado capítulo sobre a zona cinza em Os afogados e os sobreviventes, livro destinado aos jovens que "pedem clareza, o corte claro" que reduz "[...] os conflitos aos duelos, nós e eles, os atenienses e os espartanos, os romanos e os cartagineses" (Idem). ${ }^{19}$ Se a narrativa é necessária, pois ela organiza a memória, ela também não pode ser simplificadora demais. O mesmo desafio se impõe aos conceitos, e aí o próprio conceito de zona cinza, por exemplo, seria uma tentativa de compreender e fazer compreender. Como teria, no momento, pouco a acrescentar ao já analisado em vários estudos sobre esse capítulo em particular, ${ }^{20}$ gostaria de destacar a sua parte final, na qual Levi novamente usa a metáfora do espelho ao falar de Chaim Rumkowski.

\begin{abstract}
A história de Rumkowski é a história lamentável e inquietante dos Kapos e dos funcionários dos Lager [...] em Rumkowski nos espelhamos todos, a sua ambiguidade é a nossa, congênita, feita de uma massa híbrida de argila e de espírito; e sua febre é a nossa, aquela da nossa civilização ocidental que "desce aos infernos ao som de trompas e tambores", e suas pompas miseráveis são a imagem distorcida dos nossos símbolos de prestígio social [...] (SES, II, p. 1186)
\end{abstract}

Chaim Rumkowski foi, por quatro anos, o presidente ou decano (ou, como Levi prefere chamá-lo, o "ditador") do gueto da cidade polonesa de Łodz durante o domínio nazista. A descrição de Levi é implacável. Nela, Rumkowski é mostrado como alguém que, por ainda ter algum reconhecimento social por estar apenas um degrau acima de todos os demais marginalizados e perseguidos, acaba se identificando com o opressor ao adotar uma retórica discursiva semelhante a de Mussolini e Hitler, acreditando piamente no valor real do poder simbólico proveniente da própria posição ocupada no gueto, chegando a cunhar, na moeda circulante no gueto, sua própria efígie: "paradoxalmente, à sua identificação com os opressores se alterna ou é acompanhada de uma identificação com os oprimidos" (SES, II, p. 1183). Com o avanço das tropas

\footnotetext{
${ }^{18}$ Importante sublinhar aqui a presença de outra acepção possível de testemunho, tal como a vemos formulada por Dori Laub, que, em seu depoimento a Cathy Caruth (2014, p. 1120), disse: "a noção de dar o testemunho não implica simplesmente contar uma história que já existe, mas em produzir uma história no processo de endereçá-la a um ouvinte".

${ }^{19}$ Martina Mengoni mostrou como o livro tinha o jovem como um leitor preferencial, o jovem que cresceu na Itália politicamente convulsionada da década de 70. cf. MENGONI, 2015, p. 154-5.

${ }^{20}$ Para o conceito, cf. BRAVO 2019: 221-40; CAVAGLION 2006; LANGER 2001; MACÊDO 2014: 127-48; PETROPOULOS \& ROTH, 2005. Para a sua contextualização, conferir a reconstrução feita por Robert S. C. Gordon. (2012, p. 3038-201).
} 
soviéticas, o gueto de Łodz seria liquidado pelos alemães, e o seu fim seria o mesmo de milhões de outros judeus: a câmara de gás: "uma história como esta não é fechada em si mesma [...] Grita e clama para ser interpretada, porque nela se deixa ver um símbolo, como nos sonhos e nos sinais do céu" (SES, II, p. 1185). Uma história que "grita e clama para ser interpretada", "uma narrativa limite" (MENGONI, 2018, p. 50), como disse Martina Mengoni, uma história, portanto, capaz de nos desafiar.

Temos em Rumkowski um personagem individualizado, alguém que talvez tenha agido inconscientemente de acordo com "o modelo do 'herói necessário', que então dominava toda a Europa e que havia sido cantado por D'Annunzio" (SES, II, p. 1183). Merece atenção a palavra "herói", pois ela faz de Rumkowski uma figura familiar: sua relação com o poder é a nossa, sua representação de si mesmo como figura heroica e seu desejo de protagonismo e controle da própria situação estão perigosamente ligadas ao esquecimento de "nossa fragilidade essencial [...] esquecendo que nos guetos estamos todos, que o gueto é cercado, que fora do recinto estão os senhores da morte, e que não muito longe nos espera $o$ trem" (SES, II, p. 1186). Novamente encontramos uma imagem do limite: o limite demarcado pelos atuais muros dos campos, agora invisíveis ou menos visíveis, que separam o leitor de Os afogados e os sobreviventes dos "senhores da morte".

Como fazer com que esse leitor ${ }^{21}$ se sinta desafiado e, portanto, se fragilize com o reflexo de Rumkowski? Lendo Primo Levi, dois caminhos parecem pouco recomendáveis. $\mathrm{O}$ primeiro seria o percorrido por tendências de vanguarda, criticadas como "uma moda nos anos 70 e que jamais me agradou" (SES, II, p. 1199), qual seja, a da ideia de que "[...] a incomunicabilidade seria um ingrediente imprescindível, uma condenação à vida inserida na condição humana, e, em especial, no modo de viver da sociedade industrial [...]", e, com isso, o discurso seria somente "[...] fictício, puro ruído, um véu pintado que cobre o silêncio existencial (SES, II, p. 1199). Essas palavras estão no capítulo "Comunicar", um momento do livro direcionado para as discussões sobre a dimensão mais formal das narrativas sobre o Lager. Com sua sutileza habitual, Levi parece se esforçar em distinguir os tipos de incomunicabilidade: uma real e outra performática, uma condicionada pelas circunstâncias impostas do Lager e outra construída artisticamente. Levi, assim, relembra a situação vivida em Auschwitz: "nós vivemos a incomunicabilidade de modo mais radical: me refiro especialmente aos deportados italianos, iugoslavos e gregos [...]"

\footnotetext{
${ }^{21}$ Annette Wieviorka propõe um ótimo painel histórico da transformação social e cultural do testemunho a partir do fim da Segunda Guerra Mundial. Para Wieviorka, o testemunho, depois do julgamento de Eichmann, passa a ter uma essencial função performática, para além de comprobatória. Com isso, surge a "era do testemunho", na qual se articulam de forma estreita uma enriquecedora democratização do testemunho e sua veiculação midiática. Não podemos deixar de lembrar que o suporte tecnológico pode vir a simplificar o conteúdo a partir do meio adotado. Cf. WIEVORKA, 2006.
} 
(SES, II, p. 1200), submetidos a uma situação capaz de decidir seus destinos: "a maior parte dos prisioneiros que não sabiam alemão, ou seja, quase todos os italianos, morreram nos primeiros dez ou quinze dias após a sua chegada: à primeira vista, por fome, frio, cansaço, doença; com um exame mais atento, por insuficiência de informação" (SES, II, p. 1202). O problema, portanto, estaria em pressupor como possível e desejável a mimesis da radical solidão vivida no campo em qualquer forma literária de vanguarda. Assim, Levi nos aponta para uma interessante ironia: uma arte em geral de difícil apreensão e acesso mantém a base de uma arte formalmente mais conservadora, apoiada no realismo mimético de uma situação, ainda que empenhada em buscar os símbolos da inefabilidade. Em um ensaio anterior à publicação de Os afogados e os sobreviventes, essa posição fica bem nítida: "[...] não é verdade que a desordem seja necessária para pintar a desordem; não é verdade que o caos da página escrita seja o melhor símbolo do caos derradeiro ao qual somos destinados" (AM, II, p. 843). E não surpreende que será nesse mesmo ensaio que encontraremos uma frase cara à nossa discussão sobre o evento limite: " [...] me sinto farto dos elogios consagrados aos textos que, cito ao acaso, soam no limite do inefável, do não-existente, do grunhido animal" (AM, II, p. 841).22 Uma contradição em relação ao que ele mesmo disse sobre a impossibilidade de representar o tédio no Lager? Talvez.

O outro caminho a ser evitado é o da criação de estereótipos, tema e título de outro capítulo do livro. O equívoco do estereótipo estaria precisamente em pressupor ser possível, aos prisioneiros do Lager, o gesto da resistência heroica, e aqui a ligação com Rumkowski pode ser discreta e pontual, mas é significativa e essencial; ao menos, é assim que Levi reconstrói a imaginação possível dos seus leitores, sobretudo, jovens para quem "a ideia da prisão é concatenada à ideia da fuga ou da revolta. A condição do prisioneiro é sentida como indevida, anormal: como uma doença, em suma, que deve ser curada com a fuga ou com a rebelião" (SES, II, p. 1242). Trata-se de uma representação consolidada pelas narrativas mais populares: "o prisioneiro típico é visto como um homem íntegro, na plena posse de seu vigor físico e moral, que, com a força que nasce do desespero e com engenho agudizado pela necessidade, se debate contra as barreiras, as supera ou as infringe" (SES, II, p. 1243)", e é provavelmente esse o entendimento de Levi para personagens "positivos" (cf. Idem). A representação da vida "lá embaixo" deveria / poderia evitar tais tipos de personagens, de modo a, sobretudo, não somente fazer a crítica da representação da vontade de protagonismo e do voluntarismo, mas também mostrar o perigo político na internalização desses modelos.

\footnotetext{
${ }^{22}$ Como era de se esperar, o texto suscitou reações fortes, como de Giorgio Manganelli. Não tendo como entrar na discussão específica dos debates da cultura literária e editorial italiana daquele momento. Para uma reconstrução e análise da polêmica, cf. SCARPA 2010.
} 


\section{O limite de falar pelo outro}

O problema político de Rumkwoski parece estar em sua equivocada - para dizer o mínimo - autocompreensão do seu papel como representante de seu gueto. E o problema da representação, de ver-se como representante de terceiros, é, sem dúvida, um dos pontos mais sensíveis de Os afogados e os sobreviventes, tanto que Levi chega a pensá-lo em um plano antropológico, no qual se revela "[...] uma dificuldade ou incapacidade nossa de perceber as experiências alheias, que é tanto mais pronunciada quanto mais essas estão distantes temporalmente das nossas" (SES, II, p. 1247). Essa dificuldade em perceber o outro, porém, não era exclusiva do público ouvinte ou, no caso mais grave, de Rumkowski. O próprio sobrevivente a carregava consigo em seu testemunho ${ }^{23}$ e a consciência dessa reflexividade pode ser um poderoso antídoto contra a tentação de uma autopercepção heroica.

Vale notar como Levi fala no plural: ele fala em experiências alheias. Esse outro pelo qual fala já é complexo e heterogêneo, e aponta para uma potencial contradição ao mostrar que, apesar da reserva de Levi em relação à construção de heróis positivos, ele não abandona de todo certos parâmetros morais, como fica evidente quando lemos o seguinte: "Os 'sobreviventes' do Lager não eram os melhores [...] os portadores de uma mensagem: pelo que vi e vivi se demonstrava exatamente o contrário. Sobreviviam de preferência os piores, os egoístas, os violentos, os insensíveis, os colaboradores da 'zona cinza', os espiões" (SES, II, p. 1195). E dá contornos reais a algumas ações exemplares. Cito um: "[...] e morreu Baruch, estivador do porto de Livorno, imediatamente, no primeiro dia, porque respondeu com socos o primeiro soco que recebera, e foi massacrado por três Kapos [...]" (SES, II. p. 1195-6). Ainda que saiba jamais ter estado do lado dos piores e se soubesse inocente, Levi se via "[...] enfileirado entre os sobreviventes" (SES, II, p. 1195). O sobrevivente fala pelo outro consciente de não ter agido corretamente em algum momento, e por isso pode ter sobrevivido.

Mas o que é o sobrevivente? No mesmo capítulo, podemos encontrar-lhe duas características. O sobrevivente é um resto:

[...] não somos nós, os sobreviventes, os verdadeiros testemunhos. Esta é uma noção incômoda, da qual tive consciência pouco a pouco, lendo as memórias alheias, e relendo as minhas com a distância dos anos. Nós, os sobreviventes, somos uma minoria anômala, além de exígua, somos aqueles que, por prevaricação, habilidade ou fortuna, não tocaram o fundo. Quem o fez, quem viu a Górgona, não voltou para contar,

\footnotetext{
${ }^{23}$ Aqui temos uma noção de testemunho como "o encontro entre duas impossibilidades de testemunhar, que a língua, para testemunhar, deve ceder o lugar a uma não-língua, mostrar a impossibilidade de testemunhar" (AGAMBEN, 1998, p. 16).
} 
ou voltou mudo; mas são eles, os "muçulmanos", os afogados, os testemunhos integrais (SES, II, p. 1196)

“[...] Tive consciência pouco a pouco, lendo as memórias alheias e relendo as minhas com a distância dos anos". A distância, portanto, deixa de ser exclusivamente um processo de decantação, e passa a ser lugar de instância crítica e autocrítica, algo próximo ao que Edward Said entendeu como a experiência do tardio, como "[...] uma sobrevivência além do aceitável e do normal" (SAID, 2009, p. 33). Seria interessante ver em que medida Os afogados $e$ os sobreviventes - o último livro de Levi corresponderia ao conceito de "estilo tardio" de Said, mas, por ora, me limito a destacar como a sua caracterização da sobrevivência pode ser boa para compreendermos melhor a "distância dos anos" e, assim, tentarmos enxergar a experiência do sobrevivente e a sua sobrevivência "além do normal", pois não podemos nos permitir esquecer o fundamental: "eles [os afogados] são a regra. Nós, a exceção" (SES, II, p. 1196), sendo, claro, a exceção a expressão da negação da norma.

Poderíamos associar a anormalidade da sobrevivência à vergonha, outro assunto central de Os afogados e os sobreviventes. Todavia, como o argumento já foi bem desenvolvido por outros autores (cf. AGAMBEN, 1998, p. 81-126; BELPOLITI, 2015, p. 549-62), preferi seguir a trilha de outro sentimento também presente no livro: a angústia. ${ }^{24}$ Afinal, a sobrevivência é angustiante para o sobrevivente: "existe um quadro estereotipado, proposto infinitas vezes, consagrado pela literatura e pela poesia, acolhido no cinema [...] depois da doença, vem a saúde [...] o soldado retorna, e reencontra a família e a paz" (SES, II, p. 1187). E, como ele mesmo já havia narrado, mais de vinte anos antes, em A Trégua (1963), o afeto é outro, e não exatamente o de alívio e superação: "livrar-se do sofrimento foi um privilégio só para poucos afortunados, ou só por alguns instantes, ou para almas muitos simples. Quase sempre coincidiu com uma fase de angústia" (Idem). Mais adiante, o termo reaparece: "a angústia é conhecida por todos, desde a infância [...] é possível crer-se ou declarar-se angustiado por um motivo e sê-lo por outro totalmente diverso: acreditar estar sofrendo por causa do futuro, e, na verdade, se estar sofrendo pelo próprio passado" (Ibidem). Assim, Levi aponta para uma dissociação inerente ao afeto da angústia, um não conseguir expressar o próprio sofrimento, um equívoco na escolha da perspectiva, um olhar para o futuro ao invés de olhar o passado, ou olhar para o futuro para não direcionar sua perspectiva para o passado. E está dirigido potencialmente a todos. Mas a angústia de quem "tocou o fundo" parece ser diferente:

\footnotetext{
${ }^{24}$ Muito rica a associação feita por Anna Basevi entre tradução, estranhamento (Unheimlichkeit) e angústia. cf. BASEVI, 2017, p. 182-94.
} 
No Lager, o resfriado e a influência eram desconhecidos, mas se morria, por vezes de um golpe só, por males que os médicos jamais tiveram oportunidade de estudar. Curavam-se (ou se tornavam assintomáticas) as úlceras gástricas e as doenças mentais, mas todos sofriam um desconforto incessante, que poluía o sono e que não tem nome. Defini-los como 'neuroses' é redutor e ridículo. Talvez seria mais correto reconhecer neles uma angústia atávica, aquela da qual se sente o eco no segundo versículo do Gênesis: a angústia inscrita em cada um de nós do 'tòhu vahólu', do universo deserto e vazio, esmagado sob o espírito de Deus, mas do qual o espírito do homem está ausente; ou ainda não nasceu, ou já desapareceu (SES, II, p. 1197)

Palavra usada para caracterizar a excepcionalidade de um diagnóstico, a angústia torna-se um sentimento capaz de reunir aquele que fala como um outro (o sobrevivente) pelo outro (o 'afogado', aquele que 'tocou o fundo'). Mas a equação não fecha, pois ainda há outro tipo de sobrevivente: o integrante do Sonderkommando, o "caso limite" de colaboração, como vimos na coleta feita inicialmente e apresentada na introdução desse artigo.

Como se sabe, os "Esquadrões Especiais" 25 eram integrados por prisioneiros que trabalhavam nas câmaras de gás e fornos crematórios. Em troca, algumas vantagens materiais na alimentação e no vestuário, mas com a morte quase certa a esperar no final de, em média, três meses. Portanto, o significado aqui não era só o de aceitar o inaceitável trabalho para poder escapar à morte, mas algo além: o de sobreviver com menos sofrimento enquanto se aguardava a morte incontornável. E sobre essa função, Levi diz: "[...] através desta instituição, se tentava deslocar para os outros, e precisamente sobre as vítimas, o peso da culpa, de modo que [...] não restasse nem mesmo a consciência de ser inocente" (SES, II, p. 1176). A sobrevivência, nesse sentido, seria mais do que a antítese do normal. Seria inaceitável criar a perversa identificação de si como sujeito do próprio sofrimento. Não em vão, Levi considerou os Esquadrões Especiais o crime mais demoníaco do nazismo (cf. Idem).

Para que os integrantes sobreviventes não fossem objeto de juízos precipitados, o leitor deveria fazer "um experimento conceitual" (SES, II, p. 1180), qual seja, imaginar ser perseguido, ter direitos civis retirados, ser isolado em um gueto por meses e anos, durante os quais só se vê a morte, a fome e nenhum ou pouco contato com o mundo externo, para depois ser jogado dentro de um trem lotado, sem água nem comida, que o levaria por dias e noites rumo a um campo de concentração, a um "inferno indecifrável" (Idem). Levi, portanto, induz o leitor a imaginar que, nessas condições, ele talvez possa conceber algo essencial: o de não conseguir imaginar o que faria nas mesmas condições: "todo indivíduo é um objeto

${ }^{25}$ Para o tema, cf. MATTIODA, 1998, p. 77-8. 
de tal forma complexo que é vão pretender antecipar o seu comportamento, ainda mais em situações extremas; não é mesmo possível prever o seu próprio comportamento" (Ibidem). ${ }^{26}$ Assim, uma imagem refletida no espelho deformante seria mais do que um limite da imaginação - "então eu não posso imaginar o que eu faria em tal situação" - mas um limite sobre o desejo de controle de si e dos outros, possibilitado pelo recurso da previsão e o reconhecimento da própria complexidade.

De toda maneira, não gostaria que a angústia fosse a chave na qual pudessem ser encerrados todos os possíveis sentidos para a ideia de limite. Ao falarmos dela e, sobretudo, do caso limite dos Sonderkommando, entramos em outra dimensão do limite. Entramos nos limites do corpo doente, pois as causas das mortes não eram as regulares, mas a inominável angústia, 27 e também no limite imposto pelo corpo dos cadáveres com os quais lidavam os Sonderkommandos, que faziam, por sua vez, o serviço dos algozes. Como falamos da identidade possível com os carrascos responsáveis por essa ação nos corpos, chegamos, portanto, ao último nível do limite: o de falar dos nazistas.

\section{O limite de falar do outro}

"Exemplo extremo de violência ao mesmo tempo estúpida e simbólica [...] do corpo humano como se fosse um objeto". Esse é o trecho recortado de "Violência inútil", onde a análise de Primo Levi se concentra nos algozes, e me parece essencial na abordagem ao problema do evento limite: "eu acredito que os doze anos hitleristas tenham partilhado a sua violência com outros espaços e tempos históricos, mas que tenham sido caracterizados por uma violência inútil difusa, que tem a si mesma como fim, direcionada unicamente à criação da dor" (SES, II, p. 1211).

É normal prestarmos mais atenção ao caráter "inútil" da violência nazi. Todavia, gostaria de apontar para um pequeno detalhe da passagem: a violência inútil é também difusa. Os termos aparecem em sequência imediata. E essa articulação pode ser notada em outros textos de Levi, como, só para ficar em um caso, no prefácio para a edição italiana de Auschwitz, de Léon Poliakov, publicado já em 1968, na qual Levi escreveu: "tudo, ou quase tudo, já é bem conhecido sobre [...] as particularidades, mesmo as mais secretas, da organização dos Lager [...] por outro lado, muito pouco se sabe sobre o seu porquê" (PS, II, p. 1357). Inegável ver como, de alguma forma, o tema do evento limite já aparece quando ele diz que "muito pouco se sabe sobre o seu porquê", e, assim, palavras e ações, voluntárias ou involuntárias, de "repugnantes exemplares humanos (Himmler, Göring, Goebbels, Eichmann, Höss e muitos outros) não devem

\footnotetext{
26 Sobre a ideia de indivíduo insubstituível por outro e como essa se relaciona com um possível conceito de história em Levi, cf. ÅHR, 2011, p. 42

27 Para o tema, cf. SANTAGOSTINO, 2004, p. 136-7.
} 
ser compreendidas: são palavras e obras extra-humanas, ou até mesmo contra o ser humano (contro-umane) [...] se compreender é impossível, conhecer é necessário [...]. Auschwitz está fora de nós, mas está ao nosso redor. Está no ar" (PS, II, p. 1358).

Se pegarmos somente essa breve amostra, podemos ver a manifestação de um limite em entender o algoz ("não se sabe o seu porquê") e, ao mesmo tempo, ver nele algo difuso e indeterminado ("está no $\left.a r^{\prime \prime}\right)$. A aparente contradição se transformaria, quase vinte anos depois, em pergunta: "lógica inerente ao mal ou ausência de lógica?" (SES, II, p. 1121), e foi trabalhada em Os afogados e os sobreviventes de tal forma que me interessa, agora, menos tentar reconstruir a sua compreensão do que poderia ser inútil ("ilógico") na violência e pensar em seu aspecto difuso. Parece-me, portanto, ser possível pensar a partir de Levi como a ação do algoz se mostrará tanto mais potente e destrutiva o quanto mais difusa ela for, quanto mais "no ar" ela estiver.

Relendo o capítulo com esse propósito, identifiquei-lhe uma lógica interna coerente com a ideia de um algoz fluido: ele começa a definição de violência inútil como uma "violência que tem um fim em si mesma, voltada unicamente para a criação da dor [...] sempre desproporcional em relação ao seu próprio objetivo" (SES, II, p. 1211); no segundo passo, Levi fala do exercício da violência inútil no sofrimento do corpo nos trens absolutamente lotados de prisioneiros destinados aos campos, onde, para além da ausência de água e de comida, não havia qualquer objeto que "servisse como latrina [...] evacuar em público era angustiante ou impossível: um trauma para o qual a nossa civilização não nos prepara" (SES, II, p. 1215); no terceiro, o exercício da violência inútil é localizado no sofrimento do corpo na tatuagem, "[...] invenção auschwitziana autóctone (SES, II, p. 1220), cujo “[...] significado simbólico era claro para todos: este é um sinal indelével, do qual não sairás jamais; esta é a marca impressa nos escravos e nos animais destinados ao abate, e nisto vocês se transformaram" (Idem) - para além, claro, do fato da tatuagem ser proibida pela lei mosaica (cf. SES, II, p. 1221); no quarto, a violência inútil é mostrada no sofrimento do corpo nos idosos moribundos em suas casas no gueto. Como argumenta Levi, se o objetivo fosse o de exterminar, bastaria executá-los antes da viagem nos trens, o que não foi feito: "se é induzido a pensar que, no Terceiro Reich, a melhor escolha, a escolha imposta desde cima, fosse aquele que comportasse a máxima aflição [...] o inimigo não deveria somente morrer, mas morrer no tormento" (SES, II, p. 1221); como quinto passo, Levi identifica o exercício da violência inútil no trabalho, mais precisamente o trabalho que tem o corpo humano como objeto, e não a produtividade que pode extrair deste: "o trabalho deve ser aflitivo; não deve deixar espaço para o profissionalismo, deve ser aquele de animais [...] violência inútil também essa: útil talvez somente para destroncar as resistências atuais e a punir as resistências passadas" (SES, II. p. 1222); em 
um sexto momento, o exercício da violência inútil é percebido quando feito para fins supostamente médicos e científicos absolutamente inúteis, e que faz Levi colocar questões importantes, por exemplo, para defensores dos direitos dos animais em experimentos científicos (cf. SES, II, p. 1224); e, por fim, a percepção também da violência inútil sobre os restos mortais, sobre sua utilização para a indústria (cf. Idem), essa sendo uma violência inútil porque simbólica: "esta crueldade típica e sem escopo aparente, mas altamente simbólica, se estendia, justamente porque simbólica, aos restos humanos depois da morte: àqueles restos que toda civilização, desde a mais distante pré-história, respeitou, honrou e às vezes temeu" (Ibidem).

A esta altura, já ficou mais do que claro que, ao longo da argumentação, a violência inútil é exercida tendo em vista a degradação corporal da vítima, "de modo que o assassino sinta menos o peso da sua culpa" (SES, II, p. 1225), mas compreender como essa intenção tenha, sobretudo, seja possível justamente por causa de seu forte simbolismo. Ver o corpo como lugar da experiência extrema no contexto específico do espelho deformante produzido pela modernidade ocidental é especialmente forte e significativo, pois, como disse Renato Lessa, é através "da dor física extrema que o sujeito adquire consciência de seu corpo" (LESSA, 2008, p. 702). Não se deve jamais desconsiderar o peso dessa experiência limite para a imagem projetada no espelho deformante: nesse ponto, me parece muito precisa a colocação de Anna Bravo: "do corpo se desconfia, e com razão: é baseado na redução à condição animal, à dependência infantil, à coisa, ao número, que se mantém o sistema concentracionário para obter um controle total dos comportamentos" (BRAVO, 2006, p. 62). Por outro lado, como acrescenta a autora, o corpo também é objeto de desconfiança, porque, uma vez massificado no campo de concentração, ele se torna "[...] a antítese do modelo do protagonismo individual e de controle intelectual típico das classes médias cultas" (Idem). ${ }^{28}$

Ao vermos como o corpo é o lugar da ação do algoz, precisamos compreendê-la além de uma reconstrução psicológica das suas intenções: "não pretendo dizer que fossem feitos [os algozes] de uma substância humana perversa, diversa da nossa (havia os sádicos, os psicopatas entre eles, mas eram poucos)". Há uma dimensão coletiva presente no ação desse outro, como fica nítido quando Levi delimita tanto seu aspecto social "simplesmente tinham sido submetidos a uma escola na qual a moral corrente tinha sido revirada do avesso" (Idem) - como histórico: “[...] o mundo concentracionário não era senão uma versão [...] da prática militar

\footnotetext{
${ }^{28}$ Para o tema do corpo na obra de Levi, ver também o livro de Charlotte Ross, para quem o pensamento de Levi sobre o corpo, ou, antes, o pensamento corpóreo de Levi se daria em três níveis articulados entre si: "a relação entre mente e corpo e a valorização do corpo material como instrumento cognitivo; os limites do corpo e do self e o sujeito cindido e o corpo ampliado do pós-humanismo" (cf. ROSS, 2011, p. 11).
} 
alemã. [...] o exército dos prisioneiros no Lager devia ser uma cópia nada gloriosa do exército propriamente dito: ou para dizer melhor, uma caricatura sua" (SES, II, p. 1218).

Mais do que tentar avaliar como correta ou imprecisa a perspectiva de Levi, me interessa antes ressaltar o seu modo de argumentar: ao decompor o capítulo em algumas partes, é possível identificar mais do que um procedimento formal meticuloso, mas a reconstrução da trajetória do corpo desde a deportação até a morte, um processo muito próximo à interpretação proposta por Giuseppina Santagostino sobre a degradação da corpo descrito por Levi não somente em Os afogados e os sobreviventes, mas também em É isto um homem?. Para Santagostino, o corpo passa por mudanças de forma - ou de deformação - que atravessariam as seguintes fases: escravidão, perda de identidade, animalidade, equiparação com a matéria e morte (cf. SANTAGOSTINO, 2004, p. 35-6). Não será muito difícil verificar algo semelhante no desenvolvimento do argumento em "Violência inútil", onde todas as etapas se articulam a partir do corpo: o gueto, os trens, a entrada no campo (tatuagem), o trabalho no Lager e a morte. Nesse sentido, é social precisamente por ser uma rede articulada e complexa, não podendo ser isolado neste ou naquele momento. Deverá permanecer difuso e "no ar", e, assim, a crueldade é indiferente porque não é pessoal, mas social, ou seja, não diferencia este ou aquele ponto de uma estrutura produtiva do extermínio, estando onipresente, ainda que em graus distintos. Assim, ao fazer do corpo o fio condutor do processo de extermínio, Levi encontra nele um termo que lhe permite escapar dos perigos inerentes à conclusão de que o Lager não pode ser representado, pois o problema não é tanto a impossibilidade de compreender o algoz individualmente, até mesmo porque os indivíduos nomeados no prefácio, homens altamente poderosos durante o Terceiro Reich, são identificáveis e nomeáveis e passíveis de punição, mas Levi nos leva a reconstruir toda uma estrutura a partir do corpo, a partir do qual pode ser possível ver, refletido no espelho deformante, um sistema de cicatrizes.

Ainda percebo alguns caminhos possíveis para desenvolver o que foi exposto neste texto: o primeiro seria explorar mais alguns momentos do próprio Os afogados e os sobreviventes. Do debate sobre Levi e Jean Améry, feito no capítulo "O intelectual em Auschwitz", algo ainda poderia ser dito sobre o limite de falar como um outro de si mesmo. Ou ainda, no posfácio da correspondência com os alemães, certamente ainda haverá o que tirar para aprofundar e problematizar a discussão do limite da fala dos algozes e a fala para o público contemporâneo. Um segundo caminho seria o de entrelaçar de maneira mais rigorosa os conceitos de evento limite com os de trauma e de testemunho, algo aqui apenas insinuado. E um terceiro poderia ser o de, uma vez avançando na discussão sobre a possível relação com o conceito de trauma, tentar propor uma teoria mais abrangente sobre 
afetos e sentimentos, como alguns mencionados ao longo deste trabalho, como angústia, quando tentei discutir a fala pelo outro, e a indiferença, como foi feito durante a apresentação da experiência do limite como conhecimento da violência inútil e difusa. De toda maneira, tais questões exigem um fôlego teórico maior e um voo mais ousado do que poderia me permitir agora. Por isso, como quem tenta apenas esclarecer um pouco mais o verbete de um dicionário, me contento com a diferenciação dos significados do limite em Os afogados e os sobreviventes.

\section{Referências bibliográficas}

AGAMBEN, Giorgio. Quel che resta di Auschwitz: l'archivio e il testimone. Turim: Bolatti Boringhieri, 1998.

$\AA ̊ ㇒ H R$, Johan. "Primo Levi and the concept of History". In: PUGLIESE, Stanislao (org.). Answering Auschwitz: Primo Levi's Science and Humanism after Auschwitz. Nova Iorque: Fordham University Press, 2011.

ADORNO, Theodor. "A psicanálise revisada". In: Ensaios sobre psicologia social e psicanálise. Trad. de Verlaine Freitas. São Paulo: UNESP, 2015.

ANKERSMIT, Frank. Sublime historical experience. Palo Alto: Stanford Univeristy Press, 2005.

BASEVI, Anna. O Estranho-estrangeiro na obra de Primo Levi. Tese de Doutorado. Rio de Janeiro: Programa de pós-graduação em Letras Neolatinas /Universidade Federal do Rio de Janeiro, 2017.

BENJAMIN, Walter. Rua de mão única; Infância berlinense: 1900. Trad. de João Barrento. Belo Horizonte: Autêntica, 2013.

BELPOLITI, Marco. "Se questo è un sogno. Sogni, incubi e risvegli nell'opera di Primo Levi". In: MATTIODA, Enrico (org.) Al di qua del bene e del male: la visione del mondo di Primo Levi. Milão: Franco Angeli, 2000.

BELPOLITI, Marco. Primo Levi di fronte e di profilo. Milão: Ugo Guanda, 2015.

BORNEMARK, "Jonna. Antinomies and transcendece in Karl Jaspers's Philosophy". Sats - Nordic Journal of Philosophy, v. 7, n. 2, 2006.

BRAVO, Anna. "Il corpo e la memoria (prigionere e prigioneri)". In: MEGHNAGI, David (org.). Primo Levi: scrittura e testimonianza. Firenze: Libri liberi, 2006.

BRAVO, Anna. "Raccontare per la Storia". In: LEVI, Fabio; SCARPA, Domenico (orgs.) Lezioni Primo Levi. Milão: Mondadori, 2019.

BRAVO, Anna; JALLA, Daniele. "Primo Levi": un uomo normale di buona memoria. In: CAVAGLION, Alberto (org.). Primo Levi: Il presente del passato. Consiglio regionale del Piemonte-Aned. Giornate Internazionali di Studio 1988. Milão: Franco Angeli, 1991.

CALDAS, Pedro S. P. O conceito de evento limite: uma análise de seus diagnósticos. Tempo, v. 25, n. 3, set/dez 2019. 
CARUTH, Cathy. Listening to trauma: conversations with leaders in the theory \& treatment of catastrophic experience. Baltimore: Johns Hopkins University Press, 2014 [Ed. eletrônica].

CAVAGLION, Alberto. "Attualità (e inattualità) della zona grigia". In: MEGHNAGI, David (org.). Primo Levi: scrittura e testimonianza. Firenze: Libri liberi, 2006.

CAVALLERI, Matteo. “Imaginare 1'impensabilità. Le epistemologie del limite di Jean Améry e Primo Levi". In: LATINI, Micaela; STORACE, Erasmo Silvio. Auschwitz dopo Auschwitz: Poetica e politica di fronte alla Shoah. Milão: Meltemi, 2017.

CERRUTI, Luigi. “The best Science book ever written": storia ed epistemologia della chimica ne Il Sistema periodico. In: PIAZZA, Alberto; LEVI, Fabio (orgs.). Cucire parole, cucire molecole: Primo Levi e Il Sistema periodico. Turim: Accademia delle Scienze di Torino, 2019.

CINELLI, Gianluca. "Primo Levi e Herman Melville". In: Idem; GORDON, Robert S. C. (orgs.) Innesti: Primo Levi e i libri altrui. Oxford; Berna; Berlim; Bruxelas; Nova Iorque; Wien: Peter Lang, 2020.

DI MEO, Antonio. Primo Levi e la scienza come metafora. Catanzaro: Rubbettino, 2011.

FRIEDLÄNDER, Saul. “Introduction”. In: FRIEDLÄNDER, Saul (org.). Probing the limits of representation: Nazism and "The Final Solution". Cambridge: Cambridge University Press, 1992.

FRIEDLÄNDER, Saul. "Auseinandersetzung mit der Shoah": Einige Überlegungen zum Thema Erinnerung und Geschichte. In: KÜTTLER, Wolfgang; RÜSEN, Jörn; SCHULIN, Ernst (orgs.) Geschichtsdiskurs Band 5: Globale Konflikte, Erinnerungsarbeit und Neurorientierungen seit 1945. Frankfurt; Main: Fischer, 1999.

GORDON, Robert S. C. Primo Levi's ordinary virtues: from testimony to ethics. Oxford: Oxford University Press, 2001.

GORDON, Robert S. C. The Holocaust in Italian Culture, 1944-2010. Stanford: Stanford University Press, 2012 [ed. eletrônica].

LaCAPRA, Dominick. History in transit: experience, identity, critical theory. Ithaca: Cornell University Press, 2004.

LUCKHURST, Roger. "The genealogy of a concept". In: The trauma question. Londres: Routledge, 2008.

LaCAPRA, Dominick. "Escribir la historia, escribir el trauma". In: Escribir la historia, escribir el trauma. Buenos Aires: Nueva Visión, 2005.

LANGER, Lawrence. Holocaust testimonies: the ruins of memory. New Haven: Yale University Press, 1993.

LANGER, Lawrence. "Legacy in gray". In: KREMER, Roberta S. (ed.) Memory and mastery: Primo Levi as writer and witness. Albany: State University of New York Press, 2001.

LESSA, Renato. “La fabbrica delle credenze. Lo scetticismo come filosofia del mondo umano". In: Iride, anno XXI, n. 55, set-dez. 2008. 
LEVI, Neil and ROTHBERG, Michael. "Auschwitz and the Remains of Theory: Towards an Ethics of the Borderland". Symploke 11, 1-2, 2003.

LEVI, Primo. L'altrui mestiere [AM]. In: Opere Complete II. Org. de Marco Belpoliti. Turim: Einaudi, 2016.

LEVI, Primo. I sommersi e i salvati [SES]. In: Opere Complete II. Org. de Marco Belpoliti. Turim: Einaudi, 2016.

LEVI, Primo. Interviste postume [IP]. In: Opere Complete II. Org. de Marco Belpoliti. Turim: Einaudi, 2016.

LEVI, Primo. Pagine Sparse [PS]. In: Opere Complete II. Org. do Marco Belpoliti. Turim: Einaudi, 2016.

LEVI, Primo. Racconti e saggi [RS]. In: Opere Complete II. Org. de Marco Belpoliti. Turim: Einaudi, 2016.

LEVI, Primo. Conversazioni e interviste [CI]. In: Opere Complete III. Org. de Marco Belpoliti. Turim: Einaudi, 2018.

MACÊDO, Lucíola Freitas de. Primo Levi: a escrita do trauma. Rio de Janeiro: Subversos, 2014.

MATTIODA, Enrico. L'ordine del mondo: Saggio su Primo Levi. Nápoles: Liguori, 1998.

MENGONI, Martina. "The Drowned and the Saved": a proposed reading. in Primo Levi. In memoriam. In: CONSONNI, Manuela; ITALIANO, Federico (eds.). Sprachkunst: Beiträge zur Literaturwissenschaft. Jahrgang XLVI/2015, 2. Halbband, 2015.

MENGONI, Martina. Variazioni Rumkowski: Primo Levi e la zona grigia. Turim: Silvio Zamorani, 2018.

MIGLIANTI, Giovanni. "Al di là della pietà e dell'indignazione": Primo Levi come osservatore partecipante. In: DESTEFANI, Sibilla (org.). Da Primo Levi alla generazione dei "salvati": Incursioni critiche nella letteratura italiana della Shoah dal dopoguerra ai giorni nostri. Firenze: Giuntina, 2017.

PETROPOULOS, Jonathan; ROTH, John K. Gray zones: ambiguity and compromise in the Holocaust and its aftermath. Nova Iorque; Oxford: Berghahn Books, 2005.

ROSS, Charlotte. Primo Levi's narratives of embodiment: containing the Human. Londres: Routledge, 2011.

SAID, Edward. Estilo tardio. São Paulo: Companhia das letras, 2009.

SANTAGOSTINO, Giuseppina. Primo Levi: Metamorfosi letterarie del corpo. Moncalieri: C.I.R. V.I, 2004.

SCARPA, Domenico. "Oscuro /Chiaro": Giorgio Manganelli vs. Primo Levi. In: Storie avventurose di libri necessari. Roma: Alberto Gaffi, 2010.

SCARPA, Domenico. Leggere in italiano, ricopiare in inglese. In: Idem; GOLDSTEIN, Ann. In un'altra lingua /In another language. Turim: Einaudi, 2015.

VAN DER KOLK, Bessel. The body keeps the score: mind, brain and body in the transformation of trauma. London: Penguin, 2014. 
WIEVIORKA, Annette. The Era of the witness. Ithaca: Cornell University Press, 2006.

Recebido em 3 de agosto de 2020

Aprovado em 30 de setembro de 2020

Pedro Spinola Pereira Caldas é professor associado do Departamento de História da Universidade Federal do Estado do Rio de Janeiro (UNIRIO) e pesquisador do CNPq - nível 2. Desenvolve trabalhos na área de Teoria e Filosofia da História, já tendo publicado textos sobre historicismo alemão, mais precisamente sobre Johann Gustav Droysen e Jacob Burckhardt. Atualmente, estuda a obra de Primo Levi e o conceito de evento limite. Contato: pedro.caldas@gmail.com

ORCiD: http://orcid.org/0000-0001-9875-4545 